\title{
Las metáforas del agua: Una aproximación a la poesía de Miguel Hernández
}

\author{
Delia Campos Rodríguez \\ Universidad de Costa Rica, Costa Rica \\ del.camposro@gmail.com \\ https://orcid.org/0000-0003-1768-9652
}

Carolina Jiménez Jiménez

Universidad de Costa Rica, Costa Rica

cjcarolina5@gmail.com

https://orcid.org/0000-0001-6136-9870

Recibido: 5 de marzo 2018

Aceptado: 20 de mayo 2018

\section{Resumen:}

Este análisis se enfoca un acercamiento al entramado simbólico que alrededor de las metáforas del agua en el poemario "Cancionero y romancero de ausencias" de Miguel Hernández, para determinar la propuesta que plantea esta obra poética en el campo intrapersonal y social. Así, se concluye en que el agua es utilizada como instrumento de purificación para el poeta, no solo en cuanto a sentimientos del yo lírico, sino en la búsqueda de purificar a una sociedad española sumida en la Guerra, lo que va a representar una dualidad entre el dolor por la muerte de su hijo y el deseo de renovación y fertilización de una nueva sociedad tras el paso de la Iluvia. Por tanto, es tanto un regreso a los tesoros fundamentales de la vida como un llamado de atención que, cargado de sutileza, da cuenta del entorno social del momento.

Palabras clave: agua; amor; guerra; purificación; muerte.

Water's metaphors:

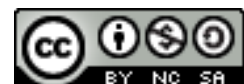

La Revista Estudios es editada por la Universidad de Costa Rica y se distribuye bajo una Licencia Creative Commons Atribución-NoComercial-Compartirlgual 3.0 Costa Rica. Para más información envíe un mensaje a 


\section{Especial: Naturaleza amena y naturaleza agreste en las letras hispánicas}

\section{An approach to Miguel Hernández's poetry}

\section{Abstract:}

This analysis focuses on an approach to the symbolic framework around the water metaphors in the poetry book "Cancionero y romancero de ausencias" by Miguel Hernández, to determine the proposal that this poetic work poses in the intrapersonal and social field. Thus, it is concluded that water is used by the poet as a purification instrument, not only in terms of feelings of the lyric self, but in the search to purify a Spanish society plunged into the war, which will represent a duality between the pain of his son's death and the desire of renew and fertilization in a new society after the rain. Therefore, it is both a return to the fundamental life treasures and a wake-up call that, loaded with subtlety, accounts for the social environment of the moment.

Keywords: water; love; war; purification; death.

\section{INTRODUCCIÓN}

En este documento se pretende un acercamiento a la poesía de Miguel Hernández, con el fin de analizar el entramado simbólico que se desarrolla en algunos poemas de "Cancionero y romancero de ausencias". Hernández fue conocido como el "poeta pastor" pues desde temprana edad debió dejar los estudios para ayudarle a su padre con el cuido de sus rebaños, por lo que durante su época infantil y juvenil estuvo expuesto al trabajo en el campo y a un acercamiento especial con la naturaleza (Esteve, 2012, pp. 16-18).

A pesar de lo anterior, el inicio de la Guerra también influyó enormemente en la producción poética de este escritor por el peligro que se vivía y por su participación personal en el conflicto. Por lo tanto, su poesía se desarrollaba mientras decidía sobre sus ideologías, en un contexto convulso de sufrimiento social, y dominaba los versos, paulatinamente, para iluminar lo cotidiano, todo bajo el compromiso de la participación del poeta en su realidad (Cano, 2009, p. 212). Durante la Guerra Civil contrae matrimonio con Josefina Manresa y de ahí nace 
Especial: Naturaleza amena y naturaleza agreste en las letras hispánicas muchísima de su poesía amorosa, mientras también lucha por superar el dolor de la muerte de personas muy cercanas a él. (Esteve, 2012, p. 41).

Con tono apasionado, se involucra en una crítica de la realidad española al responder a un mundo lleno de ansiedades dejando de lado en gran medida, en su poesía de guerra y posguerra, la idealidad de fecundidad en el paisaje y los sentidos. Así, se libera de los incentivos sensoriales para plasmar la cruda realidad de la tragedia del ser humano, y opta por mostrar a la naturaleza, pura y total, en contraposición al hombre y al odio que genera (Cano, 2009, p. 226).

Por tanto, en esta última obra poética él, desde la cárcel, da cuenta de una naturaleza que ya no percibe directamente, sino que la recuerda e imagina a través de un alma torturada y dolorida, por lo que habla de esta naturaleza a partir de lo que vive interiormente, mientras enriquece al paisaje con personificaciones y metáforas que lo hacen tomar parte activa en la cruda realidad humana (Cano, 2009, p. 227).

Un aspecto que se debe tener claro sobre la vida de Miguel Hernández es el contexto socio-histórico en el que vive pues, en gran medida, sus obras van a remitir a la Guerra Civil española, ya que tiene parte activa en este conflicto armado, aspecto que se introduce desde el año 1936, pues las "divergencias internas en la coalición del Frente Popular, y la de ésta en su conjunto con los sectores radicales del movimiento obrero [...] se produjo, a un unánime movimiento hacia la defensa armada de la república." (Tuñón de Lara et al. ,1986, p.49). Con ello en el verano del 1936 estalla la Guerra Civil Española, siendo así "una cruel contienda fratricida que constituye el hito trascendental de la historia contemporánea española y está en el origen de nuestro tiempo presente, transcurridos justo ahora ochenta años desde su comienzo." (Moradiellos, 2016, p. 11).

Ante los diversos enfrentamientos, el 4 de septiembre de 1936 se constituye el nuevo gobierno republicano presidido por Francisco Largo Caballero, pero ante 
Especial: Naturaleza amena y naturaleza agreste en las letras hispánicas las diversas crisis que enfrenta en su poder lo destituye en 1937 Juan Negrín, quien impone resistencia en el poder y refuerza su política en ayuda de un apoyo internacional desde el bando comunista; luego adquiere el poder Francisco Franco por parte del bando de los insurgentes. (Tuñón de Lara et al. ,1986, 35).

A partir de lo anterior, este análisis se justifica en la medida en que permite ahondar sustancialmente en una temática que no ha sido estudiada de manera específica, pues determina la incidencia de metáforas del agua en el poemario "Cancionero y romancero de ausencias", de Miguel Hernández, para constatar el peso que tienen en el entramado simbólico de esta obra poética. Se conforma, entonces, un documento pertinente que viene a nutrir el ya vasto corpus existente sobre la poesía de este autor, pero que lo innova al plantear un análisis de elementos puntuales para determinar, específicamente, la propuesta que subyace bajo las metáforas del agua. Por tal motivo, resulta oportuno realizar la investigación para determinar los vestigios de realidad que se distinguen en los poemas seleccionados que remiten a las condiciones convulsas de una España en guerra pues, a pesar de su sencillez léxica, el mensaje que desea transmitir el yo lírico es profundo y cargado de sentimentalismo.

De esta manera, se pretende generar un acercamiento a las diversas metáforas del agua en todas sus formas (lluvia, mar, lágrimas, etcétera), desde un punto de vista simbólico que toma en cuenta los postulados de Carl Gustav Jung sobre los símbolos y el inconsciente colectivo. Jung propone que nacemos con una especie de herencia psicológica, que no viene de lo que se ha vivido personalmente, ya que:

Así como el cuerpo humano representa un completo museo de órganos, cada uno de los cuales tiene un largo periodo evolutivo, debemos esperar que la mente esté organizada en forma semejante. No puede ser más un producto sin historia, como lo es el cuerpo en que se aloja. (Jung, 1995, p. 67).

\section{(c) (†) (-)}

La Revista Estudios es editada por la Universidad de Costa Rica y se distribuye bajo una Licencia Creative Commons Atribución-NoComercial-CompartirIgual 3.0 Costa Rica. Para más información envíe un mensaje a 
Especial: Naturaleza amena y naturaleza agreste en las letras hispánicas

De esta forma, existe una parte de la psique que predispone, entre otros, a comprender ciertos elementos de una determinada manera, y es ahí donde los símbolos entran a colación, pues son, según Jung, manifestaciones del inconsciente y:

Un nombre o incluso un cuadro que puede ser familiar en la vida diaria, que posee connotaciones específicas además de su significado convencional y obvio. Implica algo vago, desconocido u oculto para nosotros [...], una palabra o una imagen es simbólica cuando encierra algo más que su significado obvio e inmediato. Tiene un aspecto "inconsciente" más amplio que nunca es definido con precisión o explicado totalmente. (Jung, 1995, p. 20).

Y es precisamente ahí, en lo escondido, en donde ahonda esta investigación para desenmascarar lo que subyace en las metáforas que, acerca del agua, se presentan en los poemas de Cancionero y romancero de ausencias.

\section{UN ACERCAMIENTO AL ENTRAMADO SIMBÓLICO DEL AGUA EN EL TEXTO METÁFORAS DEL MAR}

El enfoque de esta investigación radica en la manera en que se desarrolla el entramado simbólico del agua, en alguna de sus variantes, en el poemario "Cancionero y romancero de ausencias" de Miguel Hernández, siendo utilizado este símbolo como una aproximación a los sentimientos de añoranza, nostalgia, reestructuración y trascendencia del yo lírico y de la sociedad que se muestra.

En el poema 17 se encuentra una de las formas particulares que tiene el agua, el mar, en tanto que hace referencia a que ahí estuvo únicamente en el pasado, "en este campo/ estuvo el mar." (Hernández, s.f., p. 8), lo que indica que ese campo es un lugar sin vida, pues el mar es fuente de vida y de transformación y, al no encontrarse el mar, la vida que en algún momento existió en este lugar se desvaneció (Cirlot, 1992, p. 298); asimismo, dentro del yo lírico se guarda la esperanza, por medio de una gota, de que vuelva el mar "Alguna vez volverá./ Si

\section{(c) (i) (2)}

La Revista Estudios es editada por la Universidad de Costa Rica y se distribuye bajo una Licencia Creative Commons Atribución-NoComercial-CompartirIgual 3.0 Costa Rica. Para más información envíe un mensaje a 
Especial: Naturaleza amena y naturaleza agreste en las letras hispánicas alguna vez una gota/ roza este campo, este campo/ siente el recuerdo del mar." (Hernández, s.f, p. 8), y por esta mínima ilusión se sigue cargando un poco de aliento vital, ahora solo presente en los recuerdos del yo lírico.

Por tal motivo, el yo lírico hace referencia a la naturaleza en la que vivió a un pasado donde probablemente fue feliz, por lo que este campo se puede asociar con España, lo que conlleva que el símbolo del mar se relacione esta vez no a la vida sino al deseo de transformación que guarda el yo lírico para su país. Con tan solo una gota de la metafórica agua del mar, se va a dar la transformación que este espacio para que renazca en un nuevo futuro, húmedo de vida, que traiga prosperidad y alegría para el pueblo español, esperanza que contrasta con el contexto de muerte que generaba por el conflicto bélico del momento.

En el poema 81 se indica que "El mar también elige/ puertos donde reír/ como los marineros." (Hernández, s.f., p. 47), con lo que se le da una personificación al mar y se afirma que él elige esos puertos en donde ser feliz. Al respecto, el agua aquí se está relacionando con un agente mediador entre la vida y la muerte (Cirlot, 1992, p. 298), por lo que se hace una referencia a que, en ocasiones, quien marca el rumbo de los acontecimientos es el contexto per se, posibilitando, en este caso, ambientes amenos y tranquilos. Este mar es "el mar de los que son", por lo que se da una determinación temporal fundamental para analizar lo que esta referencia al agua está indicando, esto porque los que son, lo que siguen vivos, siguen luchando y mantienen sus ideales inextinguibles, son quienes moldean ese mar, quienes son dueños de él y tienen la capacidad de encauzarlo hacia un rumbo social mejor.

En los versos siguientes se presenta la situación contraria, esto al indicar que "El mar también elige/ puertos donde morir/ como los marineros." (Hernández, s.f., p. 47), referencia al contexto que, en esta ocasión y tal como el mar, media, solo que ahora inclinando la balanza hacia la muerte y las consecuencias de la

La Revista Estudios es editada por la Universidad de Costa Rica y se distribuye bajo una Licencia Creative Commons Atribución-NoComercial-CompartirIgual 3.0 Costa Rica. Para más información envíe un mensaje a 
Especial: Naturaleza amena y naturaleza agreste en las letras hispánicas guerra. Por lo tanto, este mar ahora es "El mar de los que fueron." (Hernández, s.f., p. 47), ya que es un contexto que se intentó cambiar por parte de muchísimas personas que dieron la vida en el intento, y ahora ese recuerdo es lo que debe imperar.

Por otra parte, en el poema "A mi hijo" se dice que desde su muerte "diste paso al otoño y anocheció los mares." (Hernández, s.f, p. 21), en donde el otoño es una etapa en la que dejan de estar verdes y vivas las cosas, la noche es un principio pasivo de muerte que preside la formación y fertilidad al preparar para lo venidero, y el mar se concibe como elemento fluctuante entre vida y muerte (Cirlot, 1992, p. 298). Así, a pesar de que el verso pareciera plantear ideas de completo desconsuelo, el yo lírico expone su sufrimiento ante la muerte del ser amado, pero el simbolismo alrededor de la metáfora del mar implica la posibilidad de trascender y de que, aunque ahora todo sea dolor y añoranza, luego se pueda renacer o por lo menos se pueda encontrar de nuevo paz y tranquilidad.

De igual forma, versos más adelante se indica que "los consejos del mar de nada te han valido.../ Vengo de dar a un tierno sol una puñalada, de enterrar un pedazo de pan en el olvido." (Hernández, s.f, p. 21), por lo que se expone el sentido irremediable de la muerte al acabar con algo limpio y lleno de vitalidad, su hijo, a pesar de lo que le iban enseñando la vida misma y sus padres. Por tanto, a pesar de los consejos que faltaban para sobrevivir en un mundo convulso, no existió el tiempo suficiente para que aprendiera sobre la vida, ya que la muerte le llegó muy pronto.

En "Orillas de tu vientre", el yo lírico habla del encuentro sexual con su amada y especifica que "nos inspiraba el mar." (Hernández, s.f, p. 23), por lo que es razonable pensar que esta metáfora toma en consideración el contexto en el que constantemente se relacionan vida y muerte. Por tanto, el no saber qué pasará mañana o cuanto puede durar esa felicidad hace que los amantes aprovechen cada segundo para amarse con arrebato y entrega, inspirados en las

La Revista Estudios es editada por la Universidad de Costa Rica y se distribuye bajo una Licencia Creative Commons Atribución-NoComercial-CompartirIgual 3.0 Costa Rica. Para más información envíe un mensaje a 
Especial: Naturaleza amena y naturaleza agreste en las letras hispánicas cambiantes condiciones de su realidad para intentar expresar al máximo el amor que se profesan.

Además, se indica que la amada es una "Ventana que da al mar, a una diáfana muerte." (Hernández, s.f, p. 23), por lo que se representa a esta mujer como una entidad que le permite al yo lírico conocer el mundo y percibir, conscientemente, tanto lo positivo como lo negativo, ya que con su existencia presenta un punto de partida fundamental al ser su entidad beneficiosa por excelencia. Por lo tanto, aunque el yo lírico se encuentre sumido en sufrimientos, y el contexto en el que se escribió el poema constate una realidad desesperante, esa "muerte" social se ve apaciguada y llena de luz gracias a esta figura femenina.

Finalmente, en este poema se expone que "En ti me precipito como en la inmensidad/ de un mediodía claro de sangre submarina,/ mientras el delirante hoyo se hunde en mar." (Hernández, s.f, p. 23), y se toma en cuenta el simbolismo de la sangre, con su carácter vital y como sede de las pasiones, y el de la inmersión en las aguas, que tiene connotaciones de renacimiento y nueva circulación (Cirlot, 1992, p. 399). De esta forma, la sangre, que es la pasión que comparten, está ungida por la divinidad (al estar bajo el agua), y permite que los sentimientos que se profesan sean profundos y verdaderos, al tiempo que se aferran a la noción positiva de lo que la vida les ofrece.

Por otro lado, en el poema 68 se repite el símbolo del mar, pero ahora relacionado con la vuelta al útero materno (Cirlot, 1992, p. 298) pues, al regresar al útero, se va a cerrar el ciclo de la vida pero va a empezar una nueva con la intención de unirse con su amada, esto cuando el yo lírico aboga "porque tu arrullo trascienda en el mar." (Hernández, s.f, p. 37). Por tal motivo, este ser amado es una referencia a España, con la que espera que se logre cerrar un ciclo que ha sido caótico, y así comenzar una nueva vida lejos de los rencores de la guerra. Asimismo, por medio de la fecundación y fertilidad del agua, y de la metáfora de la espuma, se aborda la idea de que la vida inicia en lo acuático del cuerpo

La Revista Estudios es editada por la Universidad de Costa Rica y se distribuye bajo una Licencia Creative Commons Atribución-NoComercial-CompartirIgual 3.0 Costa Rica. Para más información envíe un mensaje a 
Especial: Naturaleza amena y naturaleza agreste en las letras hispánicas

femenino, y con ello se mantiene la esperanza de que nazca una nueva generación que por fin sea feliz.

\section{METÁFORAS DEL AGUA}

En el poema 19 aparece el símbolo del agua que, en este caso, se asocia con el corazón, ambos símbolos de vida, pues el corazón es el centro de la vitalidad humana y se vincula con el espíritu y el amor, aunque también se le puede asociar a la mayoría de los sentimientos como producto del corazón (Chevalier, 1986, p. 341). Por tanto, mientras el agua está calma, tanto el corazón como el espíritu van a estarlo también y van a ser acariciados por el sentimiento del amor, esto en el poemario cuando se indica que "el corazón es agua/ que acaricia y canta." (Hernández, s.f, p. 8), pero si el es agua es turbia, ya no va a ser portadora de vida, sino de la muerte, y por esa razón el poema da un giro al expresar que "El corazón es agua/ que se mueve, arrolla,/ se arremolina, mata." (Hernández, s.f, p. 8), con lo que si el corazón cierra sus puertas, simultáneamente se van a cerrar a la vida y al amor, y el corazón ya no va a ser portador de estos buenos sentimientos sino más bien de odio, que va a generar muerte.

Asimismo, estos corazones que en un principio son alegres y después se vuelven violentos simbolizan al pueblo español, pues en los más profundos recuerdos del yo lírico España fue un país alegre y solidario que se entretenía con el canto (poesía), pero el paso de los años que se relaciona con el paso del agua, y con la posibilidad de que los pueblos puedan abrir o cerrar sus corazones: "El corazón es puerta/que se abre y se cierra." (Hernández, s.f, p. 8). Por tanto, al cerrar los corazones también se cierran los lazos de hermandad que se comparten por medio de la sangre que fluye en sus corazones, y se acaba con vidas de pares, como sucedió en la Guerra Civil.

\section{(c) (i)(2)}

La Revista Estudios es editada por la Universidad de Costa Rica y se distribuye bajo una Licencia Creative Commons Atribución-NoComercial-CompartirIgual 3.0 Costa Rica. Para más información envíe un mensaje a revistaestudios.eeg@ucr.ac.cr. 
Especial: Naturaleza amena y naturaleza agreste en las letras hispánicas

Por otra parte, en el poema 24 el yo lírico va a expresar su nostalgia a partir de una fotografía, ya que es "un cartón inexpresivo." (Hernández, s.f, p. 10), pero por medio del agua desea volver a vivir ese momento pasado, porque el agua se asocia con el renacimiento y la nueva circulación (Cirlot, 1992, p. 54). En consecuencia, al beber esta agua el yo lírico va a revivir los momentos felices que se encuentran distantes temporalmente, como cuando indica que "Un agua de distancia/ quiero beber: gozar." (Hernández, s.f, p. 10), con la finalidad de ser feliz no solo con sus recuerdos, sino reviviendolos en cada oportunidad mientras espera por su renacimiento y por la vuelta de aquellos que, en fotografías, ahora solo son fantasmas. Lo anterior se puede asociar directamente con un desdoblamiento del escritor, quien pierde un hijo y por eso espera ese renacimiento, para que ese recuerdo que está en la fotografía vuelva a ser una realidad y pueda tener nuevamente a su hijo en sus brazos, para recuperar la felicidad que ha perdido.

En el poema titulado "Vida Solar", se introduce el concepto de agua sólida, con el paralelismo de ser ágil a la vez, pues se habla de un "agua sólida y ágil hacia el día." (Hernández, s.f, p. 17), ya que el agua sólida, como metáfora del hielo, es "la falta de calor del alma, la ausencia-del sentimiento vivificante y creador que es el amor: el agua helada representa el completo estancamiento psíquico, el alma muerta." (Chevalier, 1986, p. 60), pero al ser ágil quiere decir que el alma aún no está muerta, pues aún le queda un poco de amor que la mantiene animada, por lo cual todavía se guarda alguna esperanza de vida mientras sea de día.

Sin embargo, al llegar la noche esta esperanza que aún se encontraba presente termina por convertir esa agua sólida en lágrimas "el abismo donde lloro/ por la consumación de estas espumas." (Hernández, s.f, p. 17), y el yo lírico, en medio del dolor, espera la consumación de la espuma, lo cual da cuenta de la 
Especial: Naturaleza amena y naturaleza agreste en las letras hispánicas pérdida de la esperanza, porque añora que acabe todo el rastro que queda del agua, en forma de espuma, por lo que busca que esa vida sin amor acabe de una vez por todas.

Siguiendo con la espuma, al sacar a colación el cuerpo de la amada en el poema "Orillas de tu vientre", se habla de un "Recóndito lucero tras una madreselva/ hacia donde la espuma se agolpa, arrebatada/ de íntimo deseo." (Hernández, s.f, p. 23), por lo que aquí la espuma remite al esperma luego del encuentro sexual al que se hace referencia, como vestigio del agua dadora de vida y renovadora que deja a su paso un ambiente final de paz.

La metáfora del hielo, se puede analizar nuevamente con claridad en el poema "A mi hijo" en los versos "Ausente, ausente, ausente como la golondrina,I ave estival que esquiva vivir al pie del hielo:/ golondrina que a poco de abrir la pluma fina, naufraga en las tijeras enemigas del vuelo" (Hernández, s.f, p. 21), en el que la golondrina remite tanto a una alegoría de la primavera y a la noción de que el tiempo no se puede devolver, como a la navegación, que es un medio de alcanzar la paz y pasar a la otra orilla cruzando el mar de la existencia (Cirlot, 1992, p. 219). Por lo tanto, se compara al hijo perdido con un golondrina que murió para no tener que vivir en el hielo, perdiendo su alma al tener que ver a hermanos luchar contra hermanos y al tener que vivir en una sociedad que ya no conoce lo que es el amor. En este poema se presenta, de esta manera, el lado "positivo" de la muerte del hijo al poder estar lejos de una realidad sumamente complicada, pero se mantiene el sinsabor de tener que desprenderse de una forma abrupta y tajante de una persona que naufragó apenas empezando su navegación por la vida, y que en ese fluctuar del mar entre la vida y la muerte cayó bajo el peso de esta última.

\section{(c) (i) (2)}

La Revista Estudios es editada por la Universidad de Costa Rica y se distribuye bajo una Licencia Creative Commons Atribución-NoComercial-CompartirIgual 3.0 Costa Rica. Para más información envíe un mensaje a 
Especial: Naturaleza amena y naturaleza agreste en las letras hispánicas

El agua vuelve a ser un motivo recurrente en el poema "Orillas de tu vientre", en el que se dice que el yo lírico vive "Arrojado y fugaz como el pez generoso,/ ansioso de que el agua, la lenta acción del agua/ lo devaste: sepulte su decisión eléctrica/ de fértiles relámpagos." (Hernández, s.f, p. 23). Ahí, el pez cuenta con sentido fálico y espiritual de fecundidad y renovación, y el agua bajo nociones como la unión universal de virtudes, la creación y la inmersión que multiplica el potencial de la vista (Cirlot, 1992, p. 360), por lo que se remite al éxtasis en el encuentro amoroso que promueve la generación de nueva vida, en la figura de los hijos, y de una renovación por parte de los amantes quienes, al unirse y sumergirse en las aguas, multiplican su vitalidad y su dicha. Por tanto, la devastación del agua no se da en un sentido negativo, sino que involucra a los momentos de clímax en el encuentro del yo lírico y su amada.

Por otra parte, en el poema 68 se aborda nuevamente el símbolo del agua a la que el yo lírico desea llevar a su amada, pues uno de los versos cita que "Cerca del agua te quiero llevar." (Hernández, s.f, p. 37), ya que es símbolo de vida y de purificación y desea que su amada se llene de vitalidad. Más adelante se aclara que no solo desea llevarla ahí, sino también tenerla y sentirla en este lugar, para que su ser se llene de vida propia y de la que, por medio de la espuma (referente al contacto sexual y la fecundación), pueda promover en su vientre, pues esta otra vida sería un hijo que llene de felicidad a su amada, claro en los versos que indican un "Cerca del agua te quiero, mujer / porque la espuma te enseñe a reír." (Hernández, s.f, p. 37).

En el poema 78, llamado "Guerra", se establece que "El corazón se revuelve,/ se atorbellina, revienta./ Arroja contra los ojos/ súbitas espumas negras." (Hernández, s.f, p. 43), por lo que se homologa a la sangre del corazón con el agua de una tormenta en el mar, lo que presupone que las pasiones se ven atormentadas en el tumultuoso mundo de la guerra. De esta forma, lo que queda

\section{(c) (i) (2)}

La Revista Estudios es editada por la Universidad de Costa Rica y se distribuye bajo una Licencia Creative Commons Atribución-NoComercial-CompartirIgual 3.0 Costa Rica. Para más información envíe un mensaje a 
Especial: Naturaleza amena y naturaleza agreste en las letras hispánicas

de esta tormentosa realidad no es más que una visión de la muerte que se atestigua y por la que se llora constantemente.

Además, se dice que "El mar tiene sed y tiene/ sed de ser agua la tierra." (Hernández, s.f, p. 43), esto para hacer referencia al dolor de las madres al perder a sus hijos en el combate, lo que les deja los vientres vacíos y con ganas de nunca haber dado a luz para no tener que sufrir así. Esta referencia al vientre materno está profundamente relacionada con el agua, que es el génesis de la vida, aspecto que explica el hecho de que el mar tenga sed, pues lo que se hace es clarificar que, en la balanza entre la vida y la muerte y el fluctuar entre ambas nociones, la vida está quedando debiendo en este contexto de guerra. Además, el hecho de que la tierra tenga también sed de agua, vida y renovación remite directamente al pueblo español, quien también añora ser vida y dejar de desarrollarse en un mundo en el que en cualquier momento puede morir, ya que ni el amor puede existir.

Por su parte, en el poema 84 expresa el yo lírico que "Me descansa/ sentir que te arrullan/ las aguas.” (Hernández, s.f, p. 47), como parte de su aceptación por la muerte de su hijo, y muestra esperanza en que las aguas lo arrullen cual si fuesen su madre, con una actitud generadora de vida y de transición, llevándolo a otro lugar después de la muerte para que pueda descansar. Así, el yo lírico opta por creer que su hijo está descansando apaciblemente en algún lugar, sobre la posibilidad de renacer o de que su alma trascienda.

\section{METÁFORAS DE LA LLUVIA Y EL ROCíO}

La lluvia en el poema 50 se encuentra presente como una metáfora de un llanto enorme, el cual solo puede ser comparado en cantidad con la lluvia, representación de toda la tristeza que se encuentra presente en el yo lírico, al buscar a una persona que ya no se encuentra con él, pues indica que "Llueve. Los ojos se ahondan / buscando tus ojos: esos / dos ojos que se alejaron."

\section{(c) (i) (2) (2)}

La Revista Estudios es editada por la Universidad de Costa Rica y se distribuye bajo una Licencia Creative Commons Atribución-NoComercial-CompartirIgual 3.0 Costa Rica. Para más información envíe un mensaje a revistaestudios.eeg@ucr.ac.cr. 
Especial: Naturaleza amena y naturaleza agreste en las letras hispánicas

(Hernández, s.f, p. 18). Llorar por esa persona que ya se alejó es el peor tormento para el yo lírico, y ese sufrimiento lo entiende como celestial pues viene desde el cielo, como la lluvia y su origen divino (Chevalier, 1986, p. 671), pero al representar tanta tristeza para el yo lírico es un castigo, ya que "Llueve como si llorara/ raudales de un ojo inmenso, / un ojo gris, desangrado, / pisoteado en el cielo." (Hernández, s.f, p. 19).

En el poema 50 se presentan dos pares de ojos, unos los del yo lírico que llora como la lluvia y otros ojos en los que la lluvia cae sobre ellos, e indica que "Llueve sobre tus dos ojos." (Hernández, s.f, p. 19), pues estos ojos pertenecen a una persona que ya murió y que recibe las gotas en esta situación, esto aunado al hecho de que son unos ojos que "que pisan hasta los perros." (Hernández, s.f, p. 19), lo que da cuenta de la denigrante situación de aquellos caídos en batalla y humillados por su adversario.

Además, se reitera sobre la muerte de los otros ojos, pues el yo lírico habla de que "llueve sobre tus dos ojos / negros, negros, negros." (Hernández, s.f, p. 19), y el negro es símbolo de la muerte, de la ausencia de algo (Chevalier, 1986, p. 747), que en este caso es la vida. Además, esta lluvia quiere volver a los ojos verdes y, como el color verde es el color del paraíso, de la resurrección, de la inmortal (Chevalier,1986, p. 1057), la lluvia fecundadora simboliza la fertilización de estos ojos como semilla en el paraíso, por medio de una resurrección en este lugar que lo hará inmortal. No obstante, esto no es suficiente para el yo lírico que se pregunta si “¿Volverán a florecer?” (Hernández, s.f, p. 19), y el calor de la vida hará que florezcan nuevamente estos, pero la idea es desilusionante todavía en la tierra, en la que la lluvia va a seguir cayendo sin clemencia sobre aquellos ya sin vida.

Estos ojos que se alejaron del yo lírico y que tanto amaba, en un doblete del autor representan a los de su hijo fallecido, por lo que la lluvia es un remitente de toda su tristeza y agonía, donde lo ve como un castigo divino que unos ojos

La Revista Estudios es editada por la Universidad de Costa Rica y se distribuye bajo una Licencia Creative Commons Atribución-NoComercial-CompartirIgual 3.0 Costa Rica. Para más información envíe un mensaje a revistaestudios.eeg@ucr.ac.cr. 
Especial: Naturaleza amena y naturaleza agreste en las letras hispánicas cálidos, tiernos y llenos de porvenir se cerraran tan pronto. Por tanto, al yo lírico lo único que le queda es esperar que estos ojos que perdió en el mundo terrenal se encuentren en un lugar mejor, en un paraíso.

En el poema 51 se presenta nuevamente la metáfora de la lluvia, pero esta vez dentro de la casa del yo lírico, la cual en un principio está llena de luz y de alegría, y afirma que "Dentro de mi casa entraba / por ti la luz victoriosa." (Hernández, s.f, p. 19); no obstante, al empezar a perderse esa luz de la casa va a llegar la lluvia y reverdecer las paredes de esta casa, ya que afirma que "cuando llueve, siento/ que las paredes se ahondan, / y reverdecen los muebles, / rememorando las hojas." (Hernández, s.f, p. 20). Todo esto se teje alrededor de la idea de resucitar con el simbolismo del color verde y purificar con el simbolismo de la lluvia el lugar que ha empezado a quedarse sin luz, la cual simboliza la vida (Chevalier, 1986, p. 1057), por tal motivo la lluvia le va a dar señales de esperanza al yo lírico aunque la luz de su casa se ha empezado a apagar. Sin embargo, para el yo lírico la situación sigue empeorando pues indica que "mi casa es un ataúd." (Hernández, s.f, p. 20), lo que permite entender que a esa casa ha llegado la muerte, y la lluvia se escucha esta vez fuera de ese de ese lugar y no puede entrar a purificarla "Bajo la lluvia redobla" (Hernández, s.f, p. 20), por lo que lo único que hace esa lluvia es espantar a las golondrinas (lo irreversible del tiempo), por lo que la lluvia, a pesar de no poder purificar esa casa, va a espantar ese sentimiento de que ya nada se puede hacer, ya que aún queda alguna esperanza de vida.

Asimismo, la casa a partir del contexto en el cual se escribe el poemario simboliza a España, que en un principio era un lugar lleno de luz (vida) pero conforme avanza el tiempo esta casa comienza a tornarse oscura y va perdiendo la luz y la vida, lo que se relacionaría con una nación que con el paso del tiempo va perdiendo su esplendor a raíz de los conflictos armados y de las huelgas en aumento, y aunque la lluvia intente purificar la situación, todo va ir empeorando 
Especial: Naturaleza amena y naturaleza agreste en las letras hispánicas hasta que la casa (España) se convierte en un ataúd, pues en España la Guerra Civil trae consigo miles de muertes. Por tal motivo la lluvia se hace presente para traer purificación y un mensaje de esperanza, porque a pesar de los difíciles momentos la solución óptima es unirse como hermanos y luchar por un mejor futuro, ya que en esta casa solo cabe una ideología, dos salen sobrando "dos cuerpos en mi casa sobran." (Hernández, s.f, p. 20).

Por otro lado, en el poema "A mi hijo", se indica que los ojos de su hijo fallecido no se han cerrado, y que siguen "abiertos ante el cielo como dos golondrinas:/ su color coronado de junios, ya es rocío/ alejándose a ciertas regiones matutinas." (Hernández, s.f, p. 21), por lo que se hace referencia a su noción de sacralidad y también a la iluminación espiritual por estar entre la aurora y el nuevo día (Cirlot, 1992, p. 219). De esta forma, el yo lírico sigue sintiendo añoranza por la mirada de su hijo, a quien tiñe del sentido irreversible del tiempo con su asociación con las golondrinas. El color de los ojos, además, se dice que es rocío, por lo que la idea de renacer a una nueva vida se incluye en el poema, planteando la trascendencia del ser en una nueva mañana. Así, que los ojos tengan este color no es sino una forma de buscar esperanza ante su desgracia, esto al plantear un rechazo a la muerte y verla más como un cambio de estado en el que se está más cerca de la iluminación y de lo sagrado.

En el mismo poema, se habla de que "Hoy, que es un día como bajo la tierra, oscuro,/ como bajo la tierra, lluvioso, despoblado/ con la humedad sin sol de mi cuerpo futuro." (Hernández, s.f, p. 21), por lo que se indica que el presente, hoy, es un momento triste para el ser humano pues se siente como si estuviera bajo la tierra, es decir, como muerto en vida por la deshumanizante situación social o sintiendo inminente su muerte en este contexto violento de guerra, todo envuelto en una lluvia bajo tierra, que remite a una purificación y fertilización (Cirlot, 1992, p. 288) en la sociedad que se está dando a escondidas, en un nivel no oficial de la realidad, que responde a intereses sociales y políticos que se 
Especial: Naturaleza amena y naturaleza agreste en las letras hispánicas consideran correctos, pero que se está nutriendo por sí misma dentro de esa marginalidad.

En el último de estos versos, se habla de la "humedad sin sol de mi cuerpo futuro." (Hernández, s.f, p. 21), y se toma en consideración el simbolismo completamente negativo que carga la humedad, al ser remitente de la pasividad y de la disolución, y el del sol, a momentos de actividad heroica y a principios activos y de gloria (Cirlot, 1992, p. 245).De esta forma, se habla ahora de que el yo lírico se encuentra viviendo una muerte anticipada, en la que maneja "hoy" un cuerpo que es el que debería tener hasta que muriera, ya que en la reclusión de la cárcel se queda sin poder actuar para cambiar su situación social y sin la libertad mínima para desarrollarse en el mundo, además de que no puede cumplir con los roles de pastor, poeta y soldado que se atribuye, ya que no tiene "sol" en su cautiverio.

En el poema "La lluvia" se expresa por parte del yo lírico que "Ha enmudecido el campo, presintiendo la lluvia./ Reaparece en la tierra su primer abandono./ La alegría del cielo se desconsuela a veces,/ sobre un pastor sediento." (Hernández, s.f, p. 31), por lo que no todo es completamente para el campo, para el hombre humilde español, pues de vez en cuando encuentra pequeños momentos de calma, silencio y abandono, por lo que parece ser providencia divina (que se representa aquí con la lluvia), lo que le da a los hombres un poco de luz en estos pequeños momentos de paz.

Por su parte, en el poema 71 denominado "Después el amor" se presenta una percepción desalentadora del mundo, en el que se entiende que el odio y la guerra cuentan con todas las ventajas. A pesar de lo anterior, se indica que "Ilueve tiempo, llueve tiempo." (Hernández, s.f, p. 38), en donde la lluvia cuenta con un sentido de vida, fertilización, luz y un descenso de lo espiritual sobre la tierra, y el tiempo con el ciclo de la vida (Cirlot, 1992, p. 288), por lo que al "llover tiempo" lo que se hace es intentar apaciguar el dolor dejándolo pasar, para que la misma

La Revista Estudios es editada por la Universidad de Costa Rica y se distribuye bajo una Licencia Creative Commons Atribución-NoComercial-CompartirIgual 3.0 Costa Rica. Para más información envíe un mensaje a revistaestudios.eeg@ucr.ac.cr. 
Especial: Naturaleza amena y naturaleza agreste en las letras hispánicas

vida se encargue de sanar las heridas y de volver a colocar todo en su sitio, a pesar de que se haga de una manera lenta.

\section{PARA UNA PROPUESTA EN EL TEXTO}

A partir del análisis realizado es posible constatar que, efectivamente, las referencias a las metáforas del agua evocan a la añoranza y a la intranquilidad del yo lírico, mientras expone la crisis en el contexto, esto porque, entre los referentes metafóricos del agua, el agua es utilizada como instrumento de purificación para el poeta, no solo en cuanto a sentimientos del yo lírico, sino en la búsqueda de purificar a una sociedad española que ama y que está marcada por las miles de muertes que dejó a su paso la Guerra Civil. Por ese motivo es que se desea en el poemario que España vuelva a ser lo que una vez fue: esplendorosa, llena de luz, alegre y, principalmente, llena de vida, de ilusiones, de deseos de prosperar y de avance, pues aún quedan motivos para seguir luchando.

Asimismo, el agua de la lluvia va a representar constantemente una dualidad entre el dolor por la muerte de su hijo y el deseo de renovación y fertilización de una nueva sociedad tras el paso de estas gotas, pues se requiere que una sociedad sedienta de esperanza y de cosechas, vuelva a surgir. Por tanto, se puede afirmar que Miguel Hernández plasma en su poemario no solo sus tristezas, sino también sus deseos y esperanzas para un porvenir mejor.

De esta forma, las imágenes a las que se hace referencia a partir de la figura del agua determinan en este poemario dos claras propuestas, siendo la primera enfocada en el campo intrapersonal, al incentivar una vuelta a los tesoros fundamentales de la vida, entre ellos el amor, la familia, la paz, y la libertad, para hacer que el lector analice su situación al ver en perspectiva ciertas prioridades, todo gracias a la experiencias de un yo lírico que supo lo que fue perderlo todo menos sus memorias. Mientras que la segunda cuenta con un énfasis social, en el

\section{(c) (i) (-)}

La Revista Estudios es editada por la Universidad de Costa Rica y se distribuye bajo una Licencia Creative Commons Atribución-NoComercial-CompartirIgual 3.0 Costa Rica. Para más información envíe un mensaje a revistaestudios.eeg@ucr.ac.cr. 
Especial: Naturaleza amena y naturaleza agreste en las letras hispánicas que Hernández muestra un contexto deshumanizado, cruel, en donde el odio y los intereses políticos y económicos acaban con el presente, el pasado y el futuro de generaciones, lo que hace que el texto se tiña profundamente de un claro llamado de atención, pues expone la realidad suavizándola con metáforas tan solo para hacerla más cruda y entendible, por lo que insta a continuar la lucha hasta poder tener certeza de que se vive y actúa con la transparencia del agua, a pesar de los naufragios que se sufran y se lloren en el camino.

\section{REFERENCIAS BIBLIOGRÁFICAS}

Cano, J. (2009). La imagen de Miguel Hernández. Madrid: De la Torre.

Chevalier, J. (1986). Diccionario de símbolos. Barcelona: Herder.

Cirlot, J. (1992). Diccionario de símbolos. Barcelona: Labor.

Esteve, F. (2012). Huellas de Miguel Hernández. Madrid: Ediciones de la Torre.

Hernández, M. (s.f). CANCIONERO Y ROMANCERO DE AUSENCIAS. Revista literaria Katharsis. Recuperado de: http://revistaliterariakatharsis.org/Cancionero y romancero ausencias.pdf

Jung, C. (1995). El hombre y sus símbolos. Barcelona: Paidós Ibérica.

Moradiellos, E. (2016). La Guerra Civil española. Madrid: Lacasta.

Tuñón de Lara, Aróstegui, Viñas, Cardona y Bricall. (1986). La Guerra Civil española 50 años después. Barcelona: Labor.

\section{(c) (i) (2)}

La Revista Estudios es editada por la Universidad de Costa Rica y se distribuye bajo una Licencia Creative Commons Atribución-NoComercial-CompartirIgual 3.0 Costa Rica. Para más información envíe un mensaje a 